\title{
LA TEORÍA Y LOS VALORES EN EL DERECHO PÚBLICO: UNA INTERPRETACIÓN*
}

\author{
MARTIN LOUGHLIN \\ Professor of Public Law \\ London School of Economics and Political Science
}

\author{
SUMARIO \\ I. Las afirmaciones de Cane \\ II. La extensión de la "guerra académica" \\ III. ¿Qué es el derecho público? \\ IV. Los valores en el derecho público \\ V. La teoría en el derecho público \\ VI. Conclusiones
}

En una publicación reciente, Peter Cane planteaba un problema de cierta importancia para la disciplina, el de la relevancia de "la teoría y los valores en el Derecho Públicon. ${ }^{1}$ Cane tomaba la obra de Carol Harlow para ilustrar sus preocupaciones y argumentaba que "el debate sobre la relación entre el derecho público y la teoría política ha distraído la atención de los valores y lo ha orientado hacia las diferentes formas del estudio teórico-jurídico" (pág. 14). Lo cual es lamentable, a juicio de Cane, sobre todo porque ha conducido a una especie de "guerra académica en defensa de los respectivos ámbitos", ha producido "Cierta preocupación por las opiniones de algunos autores influyentes y por las diferentes 'tendencias en la doctrina del derecho público', en vez de análisis importantes de normas jurídicas y valores", y, también, algunos extremismos sim-

* Traducción de María Salvador Martínez y Santiago Sánchez González, Profesores de Derecho Constitucional de la Universidad Nacional de Educación a Distancia (U.N.E.D.). Trabajo publicado originalmente en la revista Public Law, en el número de primavera de 2005. Los traductores han decidido mantener el sistema de citas en las notas a pie que utilizó el autor en la publicación original del trabajo.

1 P. Cane, "Theory and Values in Public Law", en P. P. Craig and R. Rawlings, eds, Law and Administration in Europe: essays in Honour of Carol Harlow (Oxford University Press, 2003), págs. 1-21. (Las referencias a páginas que el lector encontrará en el texto corresponden a este trabajo). 
plificadores" (pág. 9). Ante esta situación, Cane proponía reorientar la discusión hacia un plano valorativo, señalando que éste ofrece una perspectiva mejor desde la que examinar la relación entre derecho y política.

El trabajo de Cane suscitó una respuesta crítica inmediata de Paul Craig, que de esa manera justificaba una de sus afirmaciones en el citado debate. Las otras siguen siendo discutibles. Dada la importancia de las cuestiones planteadas y el status de los protagonistas principales de la polémica, es difícil evitar la conclusión de que este debate interesará a todos los estudiosos del derecho público. Por lo tanto, este artículo se propone revisar los principales elementos de la discusión, ofrecer un análisis de los temas objeto de polémica y suministrar una explicación del significado de las diferentes posiciones adoptadas. Mi línea argumental tratará no sólo de mostrar las carencias de cada una de las tres posiciones diferentes que se han mantenido - las de Harlow, Cane y Craig-, sino también que sus deficiencias dimanan de un tronco común. El debate se está desarrollando en unos cauces estrechos y restrictivos, y sólo una vez que se haya admitido este punto será posible concebir una agenda más imaginativa y ambiciosa para el derecho público.

\section{LAS AFIRMACIONES DE CANE}

Nuestro punto de partida es la idea de Cane según la cual el reciente giro teórico en la doctrina del derecho público constituye una inútil desviación de la atención. Opinión que se basa en dos puntos. El primero es que "la contribución que la teoría política puede hacer para nuestro entendimiento del derecho público está limitada, de un lado, por la abstracción de los valores políticos y, de otro, por la falta de acuerdo sobre valores" (pág. 5). Observación semejante a la de W. B. Gallie sobre "conceptos básicamente disputados", de que aquellos que poseen presunciones discrepantes sobre el mundo, probablemente interpretarán conceptos generales como los de democracia, libertad y política, de maneras muy diferentes. ${ }^{2}$ Según Cane los que orientan la discusión hacia la naturaleza opinable de los conceptos que subyacen a los valores inmanentes en el tema, presentan el derecho público como una práctica más abierta y fluida que lo que es en realidad.

Su segunda afirmación, desarrollo de la primera, es que el señalamiento de las afinidades con la teoría política ha provocado que los especialistas en derecho público pierdan de vista que el derecho «es una institución normativa autoritaria, es decir, que reivindica una autoridad" (pág. 18). Cane alega que el derecho absorbe" — quiere decir, institucionaliza - ciertos valores políticos, y alo valioso políticamente se convierte en legal" (pág. 19). En consecuencia, más

2 W. B. Gallie, "Essentially Contested concepts" (1955-56), 56 Proceedings of the Aristotelian society, pág. 167. Para una elaboración de las implicaciones de la proposición de Gallie para la teoría política, véase: W. E. Connolly, The Terms of Political Discourse (2a ed., Martin Robertson, Oxford, 1983), especialmente el capítulo 1. 
que volvernos hacia los valores políticos para iluminar al derecho público, deberíamos ocuparnos del derecho público para ayudarnos a entender los valores políticos. Mediante la institucionalización selectiva de algunos de los significados de estos conceptos tan debatidos, el derecho reduce la connotación subjetiva de estos valores. Argumento similar al que usaba Luhmann cuando definía el derecho como una generalización coherente de esperanza normativa de comportamiento. ${ }^{3}$ En relación con la función actual del derecho público, Cane realiza una afirmación más concreta: "el derecho público contribuye de manera muy específica a la cultura política de una sociedad, facilitando la solución de conflictos entre valores políticos y proporcionando pautas de comportamiento cuando los valores políticos abstractos no las ofrecen" (pág. 21).

La reorientación propuesta por Cane ¿puede ayudar a la ciencia del derecho público a clarificar su agenda más inmediata?. Mi opinión al respecto es que la maniobra de trasladar el centro de la discusión de la teoría a los valores no resuelve las dificultades que Cane identifica en sus aportaciones más recientes, y no ofrece soluciones viables. La intervención de Cane nos aleja de las cuestiones principales a las que hay que responder si queremos captar el significado del giro teórico en el derecho público y determinar la relevancia de los valores en este ámbito. Pero antes de afrontar estas cuestiones, debemos situar en su contexto la propuesta de Cane y explicar las formas de la implicación de Harlow y Craig.

\section{LA EXTENSIÓN DE LA "GUERRA ACADÉMICA"}

Las alegaciones de Cane no son nuevas. En 1992, por ejemplo, publiqué un libro que empezaba por reconocer la fuerza de la primera (la naturaleza discutible y opinable de los valores políticos), y concluía con ciertas observaciones relativas a la segunda (la necesidad de identificar una estructura de autoridad). ${ }^{4}$ Así, el capítulo segundo de Public Law and Political Theory comenzaba examinando la "crisis en la filosofía política" durante los años 1950 y explicaba cómo la teoría política renació más tarde en una forma menos conceptual, "Como una provocación — que inducía a la gente a reconsiderar creencias previamente asumidas, a percibir las implicaciones más profundas de su compromiso con los valores, o quizás a reconocer la incompatibilidad entre fines igualmente perseguidos. ${ }^{5} \mathrm{Y}$, en el capítulo final, especulaba sobre si la teoría sociológica del derecho de Luhmann —y el proceso a través del cual, mediante la institucionalización, se reduce el carácter abierto y lo posible se transforma

3 N. Luhmann, A Sociological Theory of Law (E. King-Utz and M. Albrow trans., Routledge, London, 1985), pág. 82. Cf. Cane, n. 1 cit., pág. 5: «La teoría de la autopoiesis recomienda que pensemos en el derecho como algo normativamente cerrado... pero cognitivamente abierto".

4 Public Law and Political Theory (Clarendon Press, Oxford, 1992).

5 D. Miller and L. Siedentop, eds, The Nature of Political Theory (Clarendon Press, Oxford, 1983), pág. 1; citada en Public Law and Political Theory, ibid., pág. 32. 
en probable- podría ofrecer una teoría jurídica general que pudiera servir para entender el funcionamiento actual del derecho público. ${ }^{6}$ Cane, aparentemente, pone objeciones, no al "debate" en torno al derecho público y la teoría política - cuyos puntos de partida y conclusiones pueden suscitar un amplio acuerdo-, sino al método que utilizamos para movernos desde el principio hasta el final. No argumenta contra las consideraciones sobre la relación entre derecho y política, sino contra el tipo de instrumentos de análisis que se ha utilizado. La contribución de Cane no es una observación imparcial sobre la existencia de una "guerra académica": es una incursión en esa contienda.

Como trataré de mostrar, el propósito de Cane está bastante claro: defender una posición jurídica positivista. Pero su intervención es parcial, especialmente teniendo en cuenta que toma el trabajo de Carol Harlow como el objetivo principal de su análisis crítico. Puesto que el trabajo de Harlow carece de orientación teorética, no nos sirve de gran ayuda. Él recurre, desde luego, a la metáfora del semáforo (la luz roja y la luz verde)" como marco para organizar su obra Law and Administration ${ }^{7}$. Si bien abre caminos, el texto de Harlow y Rawlings es un libro con un contenido destinado a los estudiantes. Aunque destaca "la relación del derecho con la teoría política y económica", su finalidad no es "proponer una teoría propia de derecho administrativo.." Law and Administration pretendió arrojar cierta luz sobre la complejidad de la actividad administrativa y mostrar así la simplicidad implícita en ciertas formas de control judicial. Se escribió más para provocar discusión y reflexión que para defender la unidad conceptual. ${ }^{9}$ Y puesto que la metáfora es una pobre sustitución de la teoría, podemos estar de acuerdo con Cane en que la distinción luz verde/ luz roja "puede ser útil como herramienta pedagógica... (pero) como contribución a la teoría legal, resulta problemática" (pág.10) ${ }^{10}$. Sin embargo, lo hacemos sin aceptar su pretensión más general. ${ }^{11} \mathrm{Si}$ las objeciones de Cane son que la preo-

6 Public Law and Political Theory, págs. 250-259.

* Sobre la que se ha traducido como "metáfora del semáforo", véase la nota 11.

7 C. Harlow and R. Rawlings, Law and administration (Weidenfeld and Nicholson, London, 1984) y ( $2^{\mathrm{a}}$ ed. Butterworths, London, 1997), caps. 1 y 2.

8 Law and Administration, ibid. (1984), pág. xxxiii; (1997), pág.vii.

9 "No es nuestro propósito... dar respuestas simples a problemas insolubles, actitud ésta que se refleja en las preguntas incluidas en el texto. Algunas se formulan para servir de mera guía a los estudiantes a través de las dificultades de los casos. Otras, invitan a la reflexión sobre temas de interés e importancia" (ibib. pág. xxiv.)

10 Cane afirma: "No es extraño pensar que el derecho es al tiempo una institución normativa y una práctica humana dotada de un propósito; verdaderamente, es la normatividad la que hace del derecho un instrumento útil al poder y una fuente de legitimación para los que ejercen poder" (pág. 10). Cf. M. Loughlin, "Beyond Complacency" (1983) 46 M.L.R., págs. 666 a 672, donde dice que "aunque ellos (los funcionalistas) han creado una 'tendencia' o un 'dogma' (junto con una concepción instrumental del derecho), lo que la escuela crítica no ha conseguido ha sido elaborar y articular ha sido una teoría legal, (énfasis en el original).

11 Algunos de los comentaristas han detectado semejanzas en la distinción de Harlow y Rawlings entre los enfoques luz roja/ luz verde y los estilos funcionalista y normativista de pensamiento en materia de derecho público expuestos en Public Law and Political Theory, citada en la nota 4. Existen semejanzas obvias, sobre todo porque algunos de autores considerados 'red-lighters' son nor- 
cupación por la relación entre el derecho público y la teoría política ha distraído la atención, que se ha traducido en una preocupación por los "estilos" más que en un "análisis fundado", y que ha llevado a extremos simplificadores, sus argumentos en contra de la obra de Harlow no resuelven los problemas más generales. $^{12}$

Como hemos dicho, la intervención de Cane provocó una respuesta inmediata de Paul Craig, ${ }^{13}$ quien, si bien critica efectivamente el método positivista jurídico de Cane para determinar los valores en el derecho público, se aparta del problema fundamental. Sobre todo porque no proporciona una solución satisfactoria a la cuestión de la relación entre teoría y práctica. Y - lo que es significativo-, comparte con Harlow su concepción de la teoría en derecho público. Además de recurrir a la metáfora del semáforo (la luz roja y la luz verde), Harlow ha introducido una distinción entre teorías de fondo y teorías de fachada (o, en otras palabras, entre teorías profundas y teorías superficiales), que, se dice, nos ayudará a comprender el derecho público. ${ }^{14}$ Cane también critica este aspecto del trabajo de Harlow y trata de encontrar cierta consistencia en el uso de esa distinción. ${ }^{15}$ A mi juicio, Cane lleva razón: esa distinción no está clara, incluso es incoherente, y la respuesta de Craig no aborda plenamente este aspecto del debate.

Hasta este momento, por lo tanto, lo que sostengo es que los tres protagonistas del debate - Harlow, Cane y Craig- ${ }^{16}$ fracasan en su intento de abordar adecuadamente el problema de "la teoría y los valores en el derecho público". Y añado que, aunque esta división está basada en posiciones diferentes,

mativistas y los 'green-lighters' tienden a adoptar un estilo funcionalista. Pero aquellos que combinan los dos olvidan una distinción conceptual básica. Harlow y Rawlings usan las metáforas en el ámbito de una concepción instrumental del derecho: ¿debería el derecho, se preguntan, mostrarse como control (luz roja) o medio para facilitar (luz verde) el ejercicio de las competencias administrativas? Esta concepción, que es la expresión del método funcionalista, no es el fundamento adecuando para elaborar una teoría del derecho. Sea lo que fuere, el derecho público es una forma de ordenación, no es un instrumento de control; no es un mecanismo para controlar o facilitar la acción social, sino una actuación que organiza y despliega poder $-\mathrm{y}$ de ese modo posibilita mediante el control.

12 En este punto, habría que apuntar que Public Law and Political Theory aborda directamente las afinidades entre el derecho público y la teoría política, dirige la atención a las diferentes "tendencias en la doctrina del derecho público" y presenta éste como un discurso polarizado. En su trabajo, Cane expresa sus críticas, utiliza la metáfora de la luz roja y verde para ilustrarlas y escribe que "Loughlin... establece una distinción parecida en términos de 'normativismo' y 'funcionalismo'." (pág. 9).

13 P. P. Craig, "Theory and Values in Public Law: A Response", en Law and Administration in Europe, n.1 cit., págs. 23-46.

14 Carol Harlow, "Changing the Mindset the Place of Theory in English administrative Law" (1994) 14 O.J.L.S., pág. 419, en págs. 421-427.

15 Cane, n. 1 cit., págs. 5-9. Cane recupera cierto sentido mediante una reformulación de los términos como valores críticos y valores inmanentes.

16 Conviene apuntar que Carol Harlow es un actor involuntario en este debate (yo paso por alto la cuestión de si es o no propio de profesores universitarios reunirse para homenajear a un $\mathrm{CO}^{-}$ lega sólo para discutir entre ellos). Sin embargo, puesto que otros han aludido a su trabajo y representa por sí mismo un enfoque particular del derecho público, me serviré de ella como ejemplo de la posición funcionalista. 
existe un consenso que subyace en el trabajo de los tres: una visión positivista compartida, en el sentido de una creencia en que el conocimiento (científico) de un tema se adquiere por inferencia lógica de hechos demostrables empíricamente. ${ }^{17}$ Este método positivista común, que parte de una clara distinción entre hechos y valores, apuntala todas las explicaciones y es la raíz de las dificultades con que estos autores tropiezan para exponer la importancia de la teoría y de los valores en el derecho público. A fin de verificar que así es, procederé a continuación a examinar cada uno de los tres ingredientes del trabajo de Cane: "los valores en el derecho público", "la teoría en el derecho público" y el propio "derecho público". Antes de entrar en los temas de "los valores" y de "la teoría", consideraré la naturaleza del derecho público.

\section{III. ¿QUÉ ES EL DERECHO PÚBLICO?}

A pesar de debatir sobre "la teoría y los valores en el derecho público", ni Cane ni Craig dicen qué entienden por derecho público. Cuestión que es, sin embargo, esencial. A menos que identifiquemos claramente el objeto del problema, cualquier discusión sobre los valores o la teoría "en" el derecho público inducirá a confusión o se convertirá en un juego de despropósitos.

Con objeto de progresar con la cuestión de la definición, interesa destacar una división de opinión entre los diferentes protagonistas que resulta básica. Me refiero a la que existe entre las diferentes posiciones sobre la idea de que el derecho es una disciplina autónoma. Aunque pueden disentir sobre su naturaleza precisa, Cane y Craig están de acuerdo en que el derecho es un concepto normativo; Harlow, en cambio, acepta una premisa básica del pensamiento jurídico funcionalista, cual es que el derecho moderno adquiere su identidad sólo como una función de la sociedad. La divergencia de opiniones dimana de las diferentes concepciones sobre la autonomía del derecho.

\section{EL PENSAMIENTO JURÍDICO FUNCIONALISTA}

El pensamiento jurídico funcionalista tiende a fijar su atención en los 'inputs' o en los 'outcomes', y mantiene una actitud escéptica ante los ejercicios conceptuales que cosifican la idea del derecho. Su preocupación no es si, en un sentido conceptual, el derecho es un orden normativo que controla o facilita la acción social. El objetivo funcionalista es, o examinar las condiciones socia-

17 La obra clásica al respecto es la de J. S. Mill A System of Logic ( $8^{\mathrm{a}}$ ed., Longmans, London, 1886). El nexo entre el método general y una explicación específicamente jurídico positivista del derecho público nos lo ofrece A. V. Dicey en su Introduction to the Study of the Law of the Constitution ( $8^{\mathrm{a}}$ ed., Mac Millan, London, 1915), págs. 1-34, "Outline of subject: the True Nature of Constitutional Law".

* En español cabría decir 'insumos' y 'productos', pero consideramos más recomendable dejar el texto original inglés. 
les que conducen a los políticos a adoptar creencias sobre el carácter discrecional o coactivo del derecho, o analizar el impacto social de decisiones concretas adoptadas por los legisladores, los jueces y otros poderes públicos. Para los funcionalistas, el derecho "sirve a intereses o a ideas, pero carece de valor por sí mismo". ${ }^{18}$ Los "valores en el derecho público" pueden ser progresistas o reaccionarios, justos o injustos, morales o inmorales, pero son totalmente conyunturales.

Las limitaciones de este tipo de pensamiento son evidentes: aunque los funcionalistas exploran la función del derecho como ideología, raras veces se refieren a la función ideológica del derecho. Mediante la demostración de las variadas formas de actuación del derecho para proteger determinados intereses, los funcionalistas se han revelado especialmente hábiles en la desmitificación de las reivindicaciones de la imparcialidad del derecho. ${ }^{19}$ Pero no han estado tan atentos a las formas por las que, para ser eficaz como ideología, el derecho debe, hasta un grado significativo, operar de acuerdo con sus propios criterios de lógica y equidad.

Para los funcionalistas, el derecho es esencialmente una cuestión de técnica; es un instrumento por el que una voluntad gobernante se transforma en expresión jurídica; aunque abrazado con frecuencia por aquellos preocupados por la justicia social, el método funcionalista tiene sus orígenes en la teoría positivista de Auguste Comte de que el pensamiento humano ha discurrido a través de las etapas teológica y metafísica antes de alcanzar el actual estadio científico (o positivo) ${ }^{20}$ Criticar esta postura puede parecer un ejercicio meramente retórico, pero no deberíamos hacerlo sin reconocer previamente que ésta puede invocar en su apoyo gran parte de la experiencia moderna del derecho público. La realidad empírica del derecho público, entendido como el derecho positivo relativo a la actividad del Estado, es la de un cuerpo voluminoso de medidas arcanas que regulan el negocio omnipresente del gobierno administrativo. Por lo tanto, es posible identificar a una mente académica que trabaje con el método funcionalista: esto es, la disposición proclive a la cuantificación, y la conversión de prácticas jurídicas en procesos y acontecimientos que son susceptibles de formulación como leyes científicas de causa y efecto.

\section{EL POSITIVISMO JURÍDICO}

Aunque las realidades empíricas del derecho público contemporáneo han hecho que algunos lo vean como tema poco propicio para la investigación conceptual, otros han sentido la necesidad continua de tener que identificar la ló-

18 F. L. Neumann, the rule of Law: Political Theory and the Legal System in Modern Society (Berg, Leamington, Spa, 1986), pág. 285.

19 Véase, p. ej., J. A. G. Griffith, The Politics of the Judiciary (5 $5^{\mathrm{a}}$ ed., Fontana, London, 1997); P. McAulan, The Ideologies of Planning Law (Pergamon, Oxford, 1980).

20 Véase Public Law and Political Theory, n. 4 cit., págs. 106-109. 
gica de funcionamiento del derecho público. Esto nos lleva más directamente hacia la exploración de "la teoría en derecho público" y al descubrimiento de sus valores más fundamentales. En esta tarea el impulso principal ha sido recurrir a la filosofía para que nos ayude a identificar, bien una estructura general, bien algún conjunto de principios ordenadores que mantengan unido el todo como algo coherente.

Según Cane, esa filosofía es el positivismo jurídico. A juicio de los positivistas, el derecho es un orden de gobierno creado de acuerdo con las prácticas constitucionales del Estado comúnmente aceptadas. Derecho aquí significa derecho positivo, aquellas normas que han sido aprobadas mediante procesos formalmente reconocidos como procedimientos de elaboración de normas jurídicas. Pero, aunque se considera al derecho como el producto de una voluntad, eso no significa que sea arbitrario o coyuntural; a los positivistas no les está vedado pretender que este cuerpo legal forme un ordenamiento relativamente coherente. Dado que los positivistas aceptan que el derecho tiene un propósito (que existe para regular la conducta humana), son capaces de identificar ciertos valores que sirven de soporte de las constantes estructurales de un ordenamiento jurídico existente. ${ }^{21}$ Este parece ser el que Cane considera su método. Pero, ¿cual es su objeto?

Para los positivistas jurídicos, el derecho público no constituye una disciplina separada con su propia lógica y método. Si el derecho es el conjunto de normas promulgadas por los que tienen legítimamente el poder normativo, es posible diferenciar el derecho público de otros tipos de derecho sólo en virtud de su particular objeto. El derecho público, para el pensamiento positivista, es ese cuerpo de derecho positivo destinado a regular la actividad de las instituciones de gobierno de un Estado. Los positivistas sostienen que pueden revelar los valores subyacentes de ese ordenamiento mediante el examen del modelo formado por ese cuerpo legal.

\section{EL DERECHO QUe ESTÁ DETRÁS DEL DERECHO}

Muchos juristas se sienten incómodos si tienen que reconocer abiertamente que el derecho es el producto de la voluntad humana. Si el derecho es pura y simplemente el que ha sido aprobado por las autoridades de gobierno, existe el peligro de que el ejercicio positivista se desintegre en el molde del método funcionalista. ${ }^{22} \mathrm{Si}$ el derecho es una mera técnica de gobierno, entonces

21 Véase, p. ej., J. Raz, "The Institutional Nature of Law”, en J. Raz, The Authority of Law: Essays on Law and Morality (Clarendon Press, Oxford, 1979), cap. 6.

22 Hay que apuntar aquí que cuando se requiere a quien adopta un método funcionalista para que manifieste su entendimiento del concepto de derecho, invariablemente adopta una versión positivista. Cfr. Raz, ibid., pág. 37: "se admite generalmente que el positivismo jurídico es esencialmente independiente (aunque no históricamente desconectado) tanto del positivismo de la filosofía decimonónica [es decir, el positivismo de Comte y Mill], como del positivismo lógico del presente siglo". 
puede ser utilizado como un instrumento de opresión tantas veces como puede servir como un medio para preservar o promover la libertad. O sea, la explicación de su unidad estructural puede no revelar un conjunto de valores alineados con las ideas que comúnmente se tienen de la justicia. En consecuencia, los juristas que creen que el concepto de derecho está estrechamente unido a ciertos ideales —ideales agrupables bajo la etiqueta general de "justicia" — tienden a buscar "el derecho detrás del derecho". ${ }^{23}$ Preocupados por la idea del derecho entendido simplemente como el resultado de procesos normativos fruto de los órganos de gobierno, estos juristas promueven una concepción del derecho entendido como una forma de coacción sobre aquellos que detentan el poder político.

A través de la historia, este tipo de ejercicio de jurisconsulto ha implicado la búsqueda de alguna fuente suprahumana de autoridad legal. Periódicamente, la humanidad ha tratado de justificar la autoridad y la estabilidad del derecho invocando como fuente de las normas jurídicas los preceptos de una divinidad (derecho divino), o las constantes ínsitas en la naturaleza (derecho natural), o, subsidiariamente, argumentando que son el producto de las costumbres, dando a la costumbre el significado de "segunda naturaleza". ${ }^{24}$ Para muchos, sin embargo, los modernos movimientos de la ilustración, la secularización, y el desarrollo científico y tecnológico - junto con las tensiones existentes en cada una de estas explicaciones ${ }^{25}$ - han minado el poder de tales explicaciones. Sobreviven en la época moderna principalmente en una forma kantiana, en virtud de la cual el derecho debe entenderse como una serie de preceptos inscritos en la estructura de la razón humana. El derecho, dicen los anti-positivistas, no es voluntas, sino ratio; no es fundamentalmente una cuestión de voluntad, sino un rasgo de la razón.

Los principales exponentes contemporáneos de este argumento dentro del derecho público británico son Sir John Laws y T.R.S. Allan. El núcleo de sus propuestas, que no será desarrollado aquí, es que existe un derecho público «de rango más elevado" que comprende un conjunto de principios racionales que

23 Esta expresión tiene abolengo, pero dentro de las obras en inglés deriva probablemente del uso de Bacon de la expresión "la ley de leyes", como pauta indicativa para hacer buenas leyes: F. Bacon, "On the Dignity and Advancement of Learning", en F. Bacon, Works, (J. Spedding ed., Longmans, London , 1870), vol. 5, pág. 89. Más recientemente, véase: J. Dickinson, "The Law behind the Law" (1929) 29 Columbia Law Review, págs. 113-146, págs. 285-319.

24 Cf. Blaise Pascal, Pensées, i.42: "La costumbre es una segunda naturaleza que destruye la vieja. Pero ¿qué es la naturaleza? ¿Por qué no es natural la costumbre? Temo que esta naturaleza es en sí misma una primera costumbre, de la misma manera que la costumbre es una segunda naturaleza." La formulación de Pascal proviene, parece, de Montaigne, Essays, iii. 10: "Demos el nombre de Naturaleza a las costumbres y condiciones de cada uno de nosotros... El acostumbramiento es una segunda naturaleza y no menos poderosa."

25 Consideren, p. ej., el argumento de Leibniz de que si el derecho divino es sencillamente el producto de la voluntad de Dios no hay razón para considerarlo bueno: «Pues por qué alabarle por lo que ha hecho si sería igualmente digno de alabanza si hubiera hecho lo contrario? ¿dónde se hallarán su justicia y su voluntad si no queda nada sino cierto poder despótico, si la voluntad toma el lugar de la razón...?n: G. W. Leibniz, Political Writings (P. Riley ed., $2^{a}$ ed., Cambridge University Press, 1988), pág. 6. 
funcionan para mantener la libertad. ${ }^{26}$ Correctamente entendidos, estos principios de rango más elevado, que pueden encontrarse integrados en el common law, actúan para imponer una estructura más coherente en la miríada de normas, reglamentos y prácticas del derecho público. Un grupo fundamental de ideas ordena el material jurídico existente y determina su significado.

El uso de este método racionalista con la finalidad de imponer una unidad estructural en el derecho asegura que, a diferencia de la visión funcionalista, no se considere al derecho como una técnica de revestimiento de la actuación política de los gobernantes: el derecho posee una unidad conceptual que garantiza que tales políticas se adopten de forma apropiada (es decir, según principios). Este método racionalista debe diferenciarse también del método jurídico positivista ya que, en contra de los positivistas, la unidad estructural no se establece mediante un método científico social para identificar sus rasgos característicos. Para decirlo con propiedad, el derecho es un depósito con sus propios valores intrínsecos, con el que el material jurídico existente debe contrastarse antes de que se le otorgue un significado jurídico concreto.

El método racionalista es característico de lo que hemos llamado el estilo normativista (liberal) en derecho público. Según esta concepción, el derecho se entiende como un concepto autónomo que incorpora ciertos valores universales derivados de los dictados de la razón humana. El derecho público no se define como un fenómeno empírico (un cuerpo de normas promulgadas, reglamentos y decisiones), sino como una entidad metafísica, un orden más elevado de principios que informan el significado de esas normas existentes. El derecho público, según esta idea normativista, no debe concebirse como un instrumento de poder; es, más bien, un límite o control sobre el ejercicio de ese poder. No debe concebirse como una expresión de voluntad, sino como una elaboración de la razón. No es un fenómeno empírico, sino metafísico, y está constituido más como un discurso filosófico que como un discurso científico.

\section{EL DEBATE SOBRE EL DERECHO PÚBLICO}

Si no identificamos la concepción del derecho público que se invoca, el debate en derecho público no tiene sentido. Para Cane y los positivistas, el derecho público es el cuerpo de derecho positivo que regula la actividad del Estado. Según sugieren, es posible identificar sus valores esenciales mediante el análisis de la configuración de ese cuerpo normativo. En opinión de Harlow y los normativistas, sin embargo, el derecho es una técnica de gobierno. En conse-

26 J. Laws, "Is the High Court the Guardian of Fundamental constitutional rights?" (1993) P.L., pág. 59; J. Laws, "Law and Democracy" (1995) P.L., pág. 72; T. R. S. Allan, Law, Liberty and Constitutional Justice: Legal Foundations of British constitutionalism (Clarendon Press, Oxford, 1993); T. R. S. Allan, Constitutional Justice: A Liberal Theory of the Rule of Law (Oxford University Press, 2001). Como análisis, véase T. Poole, "Back to the Future? Unearthing the Theory of Common Law Constitutionalism” (2003) 23 O.J.L.S., pág. 435. 
cuencia, la naturaleza del derecho público se muestra, no examinando valores estructurales, sino exponiendo las filosofías políticas de los que controlan los distintos órganos del Estado. Los normativistas, en cambio, tienen una idea más elevada del concepto de derecho público. A diferencia de los funcionalistas y de los positivistas, los normativistas no parten del material existente de derecho positivo, sino de una concepción normativa a priori del derecho entendido como una estructura coherente de principios (morales), y consideran los actos, medidas y decisiones sólo como fuentes del derecho (en sentido estricto).

Con el permiso de Cane, esta caracterización de teorías del derecho público nos permite ubicar algunas posiciones clave en el debate. Ahora somos capaces de ver por qué les preocupa a los ius publicistas funcionalistas conocer las distintas filosofías de gobierno (y, especialmente, las ideologías de los que ocupan cargos públicos). Esta caracterización puede también servir para explicar por qué Cane considera que fijarse en las filosofías políticas distrae la atención, y pretende trasladar el análisis a los valores de derecho publico institucionalizados en el derecho positivo. Pero cuando critica a Harlow y al método funcionalista, Cane no se compromete con el enfoque de aquellos normativistas que ofrecen una versión alternativa del derecho publico como unidad estructurada - la que expresa la convicción de que el derecho público constituye un orden más elevado de principios fundamentales que gobiernan una sociedad política. Aunque Craig inicia su participación en el debate en este punto, su alegato no postula de forma inequívoca una concepción del derecho público como un orden más elevado de principios. La posición de Craig es más complicada, y sus argumentos obscurecen más que clarifican las cuestiones esenciales.

La disposición inicial de Craig es partir de un método positivista para analizar material jurídico a fin de descubrir una estructura que dé sentido al derecho positivo. Lo cual no sorprende, dado que ese es el enfoque analítico inglés ortodoxo. Pero como expositor principal del método analítico, Craig reconoció más rápidamente que la mayoría que se estaban produciendo cambios importantes en los fundamentos (del derecho) y, como consecuencia de los mismos, se estaba introduciendo cierta confusión en sus categorías tipo. De ahí que, durante algún tiempo, Craig haya tratado de reconstruir el derecho público.

Este proyecto ambicioso se hizo evidente en su investigación de largo alcance sobre la obra reciente de los científicos de la política y de los filósofos políticos, que aparentemente pretendía revelar la lógica inherente del derecho público moderno. ${ }^{27}$ Dada la naturaleza de esta obra - y especialmente los análisis detenidos de varias filosofías políticas - no sorprende que mostrara su desacuerdo con la afirmación de Cane de que la preocupación del ius publicista por la teoría política es una distracción. Pero aunque el hilo conductor de la obra de Craig consiste en sugerir que la teoría política puede enriquecer nuestro entendimiento de los valores del derecho público, su método no está claro.

27 P. P. Craig, Public Law and Democracy in the United Kingdom and the United states of America (Clarendon Press, Oxford, 1991). 
Si bien reconoce que «es importante ser claro respecto a la relación entre el derecho público, la teoría jurídica y la teoría polítican, ${ }^{28}$ en Public Law and Democracy parecía incapaz de ofrecer un razonamiento plausible sobre la naturaleza de las relaciones entre el derecho público, la filosofía política y la ciencia política. ${ }^{29} \mathrm{Y}$ esto es precisamente por lo que Brendan O'Leary, un politólogo, apuntó que el libro equivalía a "una transgresión sin propósito y a una pérdida de la fe en los estudios jurídicos" ${ }^{30}$ Cane, por lo tanto, puede tener algo que decir respecto del uso de la teoría política por los ius publicistas, si su objetivo inconfesado- es Craig y no Harlow. Pero lo más decepcionante es que Craig insiste en eludir los problemas metodológicos en su réplica a Cane. ${ }^{31}$

Hemos señalado la evolución de los trabajos de Craig en esta materia por una razón específica. Consideramos que su método principal —la técnica positivista de análisis - se apoya en una dicotomía hechos-valores, que impide realizar conexiones entre ambos elementos de una manera útil. A la pregunta de si se puede encontrar una unidad estructurada del derecho a través de un método analítico o si, para ello, es preciso acudir al método interpretativo y racionalista del normativismo liberal, la respuesta de Craig sigue siendo ambivalente. En la contestación a la crítica de O’Leary, Craig evitó las dificultades del uso que hace de un método analítico y, en su lugar, se inclinó hacia la teoría de la decisión judicial basada en derechos de Dworking. ${ }^{32}$ Más tarde, sin embargo, promovió una concepción positivista (formalista) del "rule of law frente a una concepción normativista explícita. ${ }^{33} \mathrm{Y}$, posteriormente, Craig se puso del lado de los que abogaban por una posición de "common law" (frente a los positivistas jurídicos) en un debate de carácter extremadamente conceptual, y, en última instancia, bastante estéril, sobre los "fundamentos" del control judicial. ${ }^{34}$

28 Craig, n. 13 cit., pág. 43

29 Hago este comentario en M. Loughlin, "The Importance of Elsewhere" (1993) 4 Public Law Review, pág. 44 .

30 B. O'Leary, "What should public lawyers do? (1992) 12, O.J.L.S., págs. 404 a 405.

31 Craig ignoró estas cuestiones en la respuesta a O' Leary: P.P. Craig, "What should public lawyers do? A reply" (1992) 12 O.J.L.S., pág. 564. Y en un artículo posterior cuyo título indica que podría examinar estas cuestiones directamente, se eluden de nuevo las cuestiones del método; P.P. Craig, "Public law, legal theory and political theory" (2000) P. L., pág. 211.

32 Craig, "A Reply", ibid.

33 P. P. Craig, "Formal and Substantive Conceptions of the Rule of Law" (1997), P.L., pág. 467. Véase una crítica de esta propuesta positivista de Craig en D. Dyzenhaus, «Forma and Substance in the Rule of Law: A Democratic Justification for Judicial Review?", en C. Forsyth, ed., Judicial Review and the Constitution (Hart, Oxford, 2000), cap. 7.

34 Vid. P. P. Craig, "Ultra Vires and the Foundations of Judicial Review", y "Competing Models of Judicial Review", en Judicial Review and the Constitution, ibid., caps. 3 y 17; P. P. Craig y N. Bamforth, "Constitutional Analysis, Constitutional Principle and Judicial Review" (2001) P. L., pág. 763; P. P. Craig, "Constitutional Foundations, the Rule of Law and Supremacy" (2003) P. L., pág. 92. Es difícil evitar la impresión de que Craig parece creer que, sólo si puede convencer a los demás, él mismo también se convencerá al final. En un análisis incisivo, Allan de forma certera identifica la esterilidad de este debate cuando afirma: "Desarrollado en unos términos extremadamente abstractos y formales, el debate sobre el ultra vires es esencialmente un sustituto de una discusión diferente, relativa a la naturaleza, alcance y legitimidad del control judicial. Un debate predominantemente semántico ha estado apunto de ocultar lo que realmente está en primer plano, desviando nuestra 
Entonces, ¿qué es el derecho público? Ahora sí podemos dar una respuesta directa a esta pregunta: para Cane, es voluntad; para Allan, es razón; Craig es ambiguo; y Harlow no se muestra interesado en la cuestión. Todos están equivocados. El "derecho público" es un concepto autónomo (cf. Harlow) y posee una lógica específica (cf. Craig). Pero el derecho público no puede reducirse al derecho positivo (cf. Cane) y no es una subespecie de la razón moral (cf. Allan). Esta última afirmación me obliga a revelar mi posición. Dicho brevemente, considero que el derecho público es un conjunto de actuaciones relativas al establecimiento, mantenimiento y regulación de la actividad del Estado, y que la naturaleza de dichas actuaciones sólo puede comprenderse una vez que dicha actividad de gobierno se ha conceptualizado como constitutiva de una esfera autónoma, la del ámbito de la política. ${ }^{35}$

Desde esta perspectiva, el derecho público debe tomar como su punto de partida el conjunto de todas las prácticas que constituyen ese ámbito de la política. Así, en la medida en que el derecho público se refiere al establecimiento (no sólo la regulación) de la organización estatal, debe abarcar más allá de la voluntas, de la ley elaborada por los órganos del Estado (derecho positivo). El derecho público tiene una lógica propia, pero esta ratio no es la de la razón moral; es una ratio status, una forma de la razón política que trabaja para asegurar la autoridad continuada de este ámbito autónomo de la política.

Una vez provistos de estas explicaciones sobre las distintas concepciones de la naturaleza del derecho público, podemos ocuparnos ya del tema de los valores y teorías en el campo del derecho público.

\section{LOS VALORES EN EL DERECHO PÚBLICO}

En su intento de trasladar el centro del debate hacia los valores, Cane especifica aquellos valores que, a su juicio, son inmanentes al derecho público británico. Entre ellos incluye: la representación, la responsabilidad, la deferencia judicial, la distinción de los ámbitos público y privado, la equidad ante la ley, la protección del individuo, el acceso a la justicia, el poder ejecutivo, la separación del poder público, la transparencia, la participación, la defensa del interés público y la primacía del derecho comunitario (págs. 14-16). Pero parece claro que esta lista es tan discutible como ambigua, y no sólo porque en un gran número de materias de derecho público se producen conflictos de valores: entre la primacía del derecho comunitario y la representación, entre la protección del individuo y la defensa del interés público, entre el poder ejecutivo y la separación del poder público, entre la responsabilidad y la deferencia judicial,

atención hacia puros refinamientos de una doctrina formalista, susceptible de variadas interpretaciones". T. R. S. Allan, "The Constitucional Foundations of Judicial Review: Conceptual Conundrum or Interpretative Inquiry?” (2002) 61 C. L. J., págs. 87 a 101.

35 Esta argumentación se encuentra en M. Loughlin, The Idea of Public Law (Oxford University Press, 2003). 
y en muchos otros casos. En cierto modo resignado, Cane admite que estos valores "Compiten entre sí", son "dinámicos más que estáticos", e, incluso, llega a afirmar que es posible "honrar más a un valor con el incumplimiento de una norma que con su observancia" (págs. 16-17). ${ }^{36}$ ¿Cómo puede entonces un enfoque centrado en los valores contribuir a mejorar nuestro entendimiento del derecho público?

Cane admite que desviar el objeto del debate de las teorías a los valores no supone, por sí mismo, un claro avance; puesto que los valores son abstractos, "la gente puede no estar de acuerdo sobre cuáles son las normas concretas que esos valores demandan o justifican" (pág. 17). Del mismo modo, admite que esa falta de certeza alcanza incluso a los que defienden una teoría político-jurídica basada en valores concretos, como pueden ser «el pluralismo, el liberalismo, el republicanismo", en la medida en que "pueden no estar de acuerdo en los detalles de dicha teoría, esto es, en la relación que existe entre los valores que defienden y el modo en que deben resolverse los conflictos que se produzcan entre ellos" (pág. 17). En este punto, no parece que los argumentos de Cane difieran mucho de las tesis postuladas en mi obra Public Law and Political Theory. Sirviéndome de los métodos de la teoría política post-empírica, yo sugería en dicha obra que «la labor que corresponde a la teoría... es la de presentar de forma explícita nuestros pre-juicios", y esto significa que "debemos desarrollar esquemas conceptuales que sirvan para descubrir los valores inmanentes, las relaciones causales y los rasgos definitorios" de la práctica del derecho público. Previendo que es posible que surgieran entonces un gran número de esquemas conceptuales (en palabras de Cane, "cómo los valores... se relacionan unos con otros"), yo proponía que el parámetro para juzgar la utilidad de dichos esquemas, su potencial, fueran los cánones básicos de racionalidad (consistencia, coherencia, no contradicción) y, puesto que estamos ante una cuestión inmanente, también un canon que juzgara su adecuación desde el punto de vista histórico. ${ }^{37}$

La crítica de Cane consiste en que, a su juicio, aquellos que se ocupan de la relación entre derecho público y teoría política creen que "necesitamos la teoría política para poder entender el derecho público, pero el derecho público no tiene una contribución clara que hacer a la comprensión de los valores políticos" (pág. 18). A la vista de lo expuesto al final del apartado anterior sobre el concepto de derecho público, la crítica de Cane deja de tener sentido: el derecho público es inmanente a la teoría política. Dejando esto a un lado, no obstante, puede advertirse que yo sostuve que, a pesar de que la teoría política

36 El razonamiento de Cane es particularmente desconcertante desde su reciente crítica a la tesis de Dawn Oliver en Common Values and the Public-Private Divide (Butterworths, London, 1999), de que los valores comunes de autonomía, dignidad, respeto mutuo, status y seguridad subyacen a todos los aspectos de la regulación jurídica. Cane argumenta que los valores de Oliver "son tan abstractos que no es sorprendente que puedan predicarse tanto del derecho público como del derecho privado": P. Cane, "Accountability and the Public/Private Distinction" en N. Bamforth y P. Leyland, eds., Public Law in a Multi-Layered Constitution (Hart, Oxford, 2003), cap. 10, pág. 268.

37 Public Law and Political Theory, n. 4 cit., págs. 35-36. 
post-empírica muestra la dificultad de elaborar estándares de objetividad relevantes para una práctica concreta, esto no significa que nos veamos obligados a "refugiarnos en el escepticismo, en un relativismo contraproducente o en un subjetivismo irracional.. ${ }^{38}$ El núcleo de mi argumentación en el último capítulo de la obra citada era que necesitamos una determinada teoría del derecho público que permita trabajar con hechos y normas del modo menos ideológico posible (de ahí el guiño a las teorías de sistemas). Y puesto que ésta no era sino una solución esbozada, en consecuencia, he tratado de justificar mi posición. ${ }^{39}$ En cuanto a Cane, ¿ha ofrecido alguna solución?

Él sugiere que los ius publicistas necesitan observar la relación desde el otro punto de vista y preguntarse cómo puede contribuir el derecho público a la comprensión de los valores políticos. Así es, puesto que el carácter abstracto de los valores limita su fuerza normativa, debemos acudir «al derecho para afirmar qué conducta es políticamente adecuada" (pág. 20). Esta es una respuesta atrevida, simple y demasiado general. Y sólo puede tener sentido si por derecho entendemos el derecho positivo - las normas aprobadas por los correspondientes órganos del Estado con potestad para ello- Pero, ¿es convincente?

La cuestión más importante es la siguiente. Gran parte de la estructura y del modelo constitucional británico, no sólo no tienen su origen en el derecho positivo, sino que, incluso, en ocasiones, son el resultado de una práctica contraria a ese derecho; por eso, la afirmación de Cane resulta indefendible. En Inglaterra, la actuación constitucional está cada vez más ordenada y formalizada, y Cane podría querer argumentar que la fuente de las normas jurídicas escritas, como el reciente "Código ministerial", se encuentra en un poder público con potestad normativa para ello. Pero esta no es una respuesta sencilla. ${ }^{40}$

Hay una segunda cuestión que debemos señalar: si se reconoce que los valores se encuentran "incorporados" al derecho como consecuencia de la decisión de un poder público, entonces ¿se materializan en él y desaparecen mediante el acto de su declaración formal? De forma correcta, Craig plantea por qué, por ejemplo, la transparencia (y no el secreto) aparece como un valor establecido, especialmente cuando hasta la aprobación de la Ley sobre libertad de información de 2000 existía muy poca base para ello. ${ }^{41}$ Esta dificultad conduce a Craig a realizar una reformulación en la línea de la lista de Cane que "define

38 Ibid., pág. 35 (citando a Bernstein).

39 Vid. The Idea of Public Law, n. 35 cit.

40 El mismo ejemplo del Código Ministerial (Ministerial Code, Cabinet Office, 2001) es discutible, porque, aunque haya emanado del Cabinet Office, no es, en sentido estricto, una publicación de dicho organismo (un Cabinet paper). Fue autorizado únicamente por el Primer Ministro (un organismo, como el Cabinet Office, prácticamente desconocido para el derecho positivo). Y, otro ejemplo, ęel sistema de gabinete es una solución arraigada en los valores básicos de la forma de organización política de Gran Bretaña?; sobre esto, vid.: C. Foster, "Cabinet Government in the Twentieth Century” (2004) nº 67 M.L.R., pág. 753.

41 Craig, n. 13 cit., pág. 24. Cfr. Local Government (Access to Information) Act 1985 y el Code of Practice on Access to Government Information ( $2^{\mathrm{a}}$ ed., Department for Constitutional Affairs, London, 1997). 
los valores que, de acuerdo con la opinión de la doctrina ius publicista, son, o deberían ser, importantes en un régimen de derecho público". ${ }^{42}$ Pero un positivista (del tipo que sea) no puede aceptar con facilidad esta propuesta. Además, al indicar que esta (mal definida) comunidad de los estudiosos del derecho público posee un conocimiento especial de la naturaleza y función del derecho público, la sugerencia de Craig revela mucho de su propio trasfondo ideológico normativista. Pero la cuestión importante es que, incluso si limitamos la propuesta de Cane a la identificación de los valores básicos mediante el análisis del derecho positivo, sigue sin estar claro que trasladar el debate desde la teoría al campo de los valores reduzca de manera significativa el grado de desacuerdo en el mismo. ${ }^{43}$

La solución de Cane, por tanto, tiene el mérito singular de la sencillez: el derecho es decisión. Pero no hay que exagerar. Cane no defiende que "el derecho tenga la naturaleza de un patrón de conducta definitivo" (pág. 20). Lo importante es que considera que el derecho puede dar «respuestas determinantes a cuestiones morales y políticas que de otro modo no podrían obtenerse", incluso en el caso de que estas respuestas puedan ser discutibles en términos morales y políticos (pág. 20). Pero, dado que busca establecer una autoridad del derecho independiente de sus orígenes morales y políticos, permanece en la posición de argumentar que el derecho es mandato y que el derecho público es dominación. Cane responde así a la cuestión de la relación entre derecho público y teoría política con la solución precisa (positivismo jurídico analítico) que mi obra Public Law and Political Theory comenzaba por rechazar. Aunque él es libre de hacerlo, podemos señalar que ciertas cuestiones básicas relativas a la consistencia, la coherencia y la eficacia de las normas de derecho público no encuentran respuesta en sus trabajos. A su juicio, una vez que tenemos una decisión normativa clara, hemos resuelto ya la cuestión constitucional. La solución que propone Cane reduce el ámbito del derecho público hasta el punto de la incoherencia.

\section{LA TEORÍA EN EL DERECHO PÚBLICO}

Llegados a este punto, cuando nos planteamos la cuestión de la teoría en el derecho público, descubrimos la razón de la naturaleza asimétrica y parcial del debate que ocupa a Cane, Harlow y Craig. Los tres protagonistas comparten una orientación positivista dirigida por el objetivo ambicioso de elaborar teorías jurídicas y, más concretamente, teorías extraídas de las ciencias naturales. Su

42 Ibid.

43 Adviértase, p. ej., la afirmación de David Feldman de que, desde la aprobación de la $H u$ man Rights Act de 1998, los valores fundamentales del ordenamiento constitucional británico incluyen los de ala dignidad, autonomía, democracia pluralista, tolerancia, mentalidad abierta, equidad y respeto al Estado de Derecho": D. Feldman, "Convention rights and substantive ultra vires" en Judicial Review and the Constitution, n. 33 cit., pág. 262. ¿Cuántas listas de valores fundamentales, sólo parcialmente coincidentes, pueden elaborarse en un único ordenamiento jurídico? 
finalidad es aislar ciertos elementos básicos de conocimiento que puedan ponerse en relación de un modo lógico y formar una estructura científica objetiva. Visto así, el debate - la "guerra académica" — en realidad se refiere a distintas variantes del positivismo, con Cane promoviendo el argumento de que el método positivista en derecho exige una estricta separación entre el ámbito del conocimiento jurídico y los ámbitos de la política, la historia y la ética. En la medida en que propugna un cambio en la dirección del debate, de la teoría a los valores, su trabajo puede interpretarse como una crítica a los positivistas, tanto a aquellos que se centran en las relaciones causales, y que producen el efecto de destruir la autonomía de la ciencia jurídica (Harlow y los funcionalistas), como a los que extienden las bondades de su método a la filosofía política y la ciencia política y, al proceder de esta manera, provocan dificultades metodológicas de difícil solución (Craig).

Cuando nos centramos en el tema de la teoría, entonces, la división fundamental es la que existe entre positivistas y anti-positivistas, o interpretativistas. Estamos ante una brecha metodológica básica que se ha puesto de manifiesto en todas y cada una de las ciencias sociales. ${ }^{44}$ Debe señalarse aquí que mi obra Public Law and Political Theory es un trabajo anti-positivista. Fue un intento de desarrollar un enfoque de la disciplina del derecho público desde una perspectiva interpretativista, y es evidente ahora que ese método confundió a algunos autores (positivistas) que comentaron dicha obra. ${ }^{45}$ Para explicar el papel que corresponde a la teoría en el derecho público es preciso apuntar los principales elementos de esas diferentes líneas de investigación.

El enfoque interpretativo se apoya en la convicción de que nosotros estamos formados, en parte al menos, por nuestros pre-juicios. En tanto en cuanto esos pre-juicios se transmiten a través del lenguaje, la idea de significado pasa a ocupar un lugar central en nuestra investigación. Y puesto que las cosas tienen significado sólo dentro de un determinado "contexto" (esto es, en relación con otras cosas), cualquier intento de dar sentido a un objeto de investigación requiere la identificación de ese ámbito. Sólo una vez que hayamos identificado el contexto podremos afirmar la coherencia o incoherencia de las afirmaciones que se realicen, lo cual exige además que tengamos una idea del "sujeto o sujetos" receptores de esos significados. Sólo es posible hablar de coherencia respecto a cualquier tipo concreto de compromiso, si existe un patrón común de significado compartido por dichos sujetos. ${ }^{46}$ Según esta corriente interpre-

44 Se puede encontrar una descripción útil en Q. Skinner, ed., The Return of Grand Theory in the Human Sciences (Cambridge University Press, 1985).

45 Vid., p. ej., el comentario de Craig, en el que afirma que la división entre normativistas y funcionalistas está injustificada con el argumento de que existe un elemento normativo en el funcionalismo y un elemento funcionalista (la determinación de unos objetivos) en el normativismo: P. P. Craig, "Review” (1993) 13 Legal Studies, pág. 275. A mi juicio, su opinión se basa en un ignoratio elenchi (N. del T.: una "ignorancia del argumento"). El comentario de Harlow se analiza más adelante.

46 Vid. la aportación clásica de C. Taylor, "Interpretation and the Sciences of Man", en C. Taylor, Philosophical Papers (Cambridge University Press, 1985), Vol. 2, cap. 1. 
tativa, la teoría es simplemente el intento de hacer mucho más comprensible un tipo concreto de compromiso.

Partiendo de esta posición, en la obra Public Law and Political Theory sostenía que el derecho público es una forma de discurso político (la identificación de "un ámbito"), en el que el significado de los conceptos básicos varía de unos autores a otros ("los sujetos") que representan diferentes concepciones del derecho público (la búsqueda de coherencia). Esta breve explicación podría ampliarse. Pero, para poder analizar las diferencias metodológicas antes señaladas, debemos comenzar por ilustrar el uso que los positivistas hacen de la teoría en el derecho público.

En el trabajo "Changing the mindset: the place of theory in English administrative law, Harlow intentaba "hacer desaparecer algunas de las ambigüedades que enturbian el debate teórico entre juristas en el ámbito del derecho público" y "examinar las posibles funciones de una teoría del derecho públiCO". ${ }^{47}$ Tras un complicado análisis en el que distingue entre teorías "de fondo" y "de fachada", y teorías "profundas" y "superficiales", ${ }^{48}$ Harlow llega a la que, obviamente, es la cuestión principal: ¿đe qué manera ... el derecho público inglés es deficiente en el plano teórico... ${ }^{49}$ No resulta tan interesante la respuesta a esta pregunta como la naturaleza de la misma. La cuestión es que esta pregunta tiene sentido sólo si la "teoría" se considera, no como un método de investigación, sino como si ella misma constituyera una determinada forma de conocimiento. Y la manera más obvia de utilizar la teoría para demostrar la validez del conocimiento jurídico es mostrar que el conocimiento jurídico es una forma de conocimiento científico. ${ }^{50}$

La predisposición positivista de Harlow la lleva a malinterpretar el argumento de Public Law and Political Theory. Probablemente está en lo cierto cuando sugiere que mi utilización de la teoría como si fuera un mapa es «esencialmente descriptiva,${ }^{51}$ pero llega a conclusiones erróneas. ${ }^{52}$ En el apartado relativo a "Teorías como mapas", explico que "la tarea que corresponde a una teoría es presentar de forma explícita y sistemática aquellas estructuras conceptuales que implícitamente determinan nuestra visión del objeto" (coherencia); que este enfoque teórico puede revelar la existencia de una diversidad de estructuras conceptuales"; y que, de acuerdo con Charles Taylor, "podemos ver esa variedad de teorías como si fueran mapas rivales de un mismo terreno"

47 Harlow, n. 14 cit., pág. 421.

48 Vid. pág. 49, cit.

49 Harlow, n. 14 cit., pág. 424.

50 Esta concepción positivista de la teoría es la que da lugar a la frase ocurrente "puede funcionar en la práctica, pero no en la teoría".

51 Harlow, n. 14 cit., pág. 427.

52 Harlow parece creer que yo estoy defendiendo que el carácter distintivo del derecho público reside en su "anatomía interna" (esto es, la distinción entre derecho público y derecho privado): ibid., pág. 427. Pero es una pretensión que yo explícitamente rechazo. Vid. Public Law and political Theory, n. 4 cit., págs. 3-4: “Ese... no es el método que yo propongo adoptar. La dificultad de adoptar esta metodología es que arranca de la presunción implícita de que el derecho es, en general, una disciplina simple, sencilla... (en lugar de) una forma sofisticada de discurso político". 
(el contexto)..$^{53}$ Las teorías no son descriptivas en el sentido que los positivistas creen; combinan descripción y valoración en un modo que los positivistas no están dispuestos a reconocer.

Además, Harlow "arroja algunas dudas" sobre mi enfoque histórico y considera que yo "me veo empujado a una disputa prolongada con la historia". ${ }^{54}$ Pero este es un uso extraño de la historia. No existe una historia que sea "aquello que realmente sucedión; la historia la construyen los historiadores y su labor es totalmente interpretación (es decir, con objeto de generar conocimiento). ${ }^{55}$ Escribir la historia es la única manera de hacer esto; «es un mundo, y un mundo de ideas. ${ }^{56}$ Todas nuestras valoraciones y afirmaciones vienen determinadas por conceptos y, en palabras de Quentin Skinner, incluso nuestros conceptos aparentemente más abstractos son completamente históricos" ${ }^{57}$ El razonamiento de Harlow conforme al cual el método interpretativo no permite identificar la especificidad del derecho público viene determinado por su creencia de que éste tiene que ser un razonamiento sobre derecho positivo (y la existencia de una división jurisdiccional entre el derecho público y el derecho privado); una conclusión, en pocas palabras, que no puede venir más que, directamente, de una forma de pensar positivista.

Craig, por su parte, comparte estas limitaciones respecto al uso de la teoría y la historia. En su respuesta a Cane comenta lo siguiente:

Existe una tendencia a considerar la teoría política como "teórica", en el sentido de que no está conectada con la realidad. Es un error. Las teorías políticas se desarrollan a partir de evidencias empíricas y convicciones, de las cuales se deducen conclusiones normativas ${ }^{58}$.

Evidentemente, Craig también está utilizando ciertos modelos teóricos positivistas extraídos de las ciencias naturales. Él explica su trabajo tomando como ejemplo el de los pluralistas de principios del siglo XX, que, según él razona, expusieron los fundamentos históricos de la concepción constitucional de Dicey. Los pluralistas aparentemente afirmaban que la concepción de Dicey se basaba en una visión unitaria del funcionamiento de la democracia: "todo el poder público era y debía canalizarse a través del Parlamento, órgano que poseía el monopolio legislativo". ${ }^{59}$ Esta idea se funda en una "concepción unitaria del Estado" que conecta con la preocupación de Hobbes por la guerra civil y la anarquía. "Una vez que revelaron los fundamentos históricos del Estado unita-

53 Public Law and political Theory, ibid., págs. 37-38.

54 Harlow, n. 14 cit., pág. 427.

55 Véase R. G. Collingwood, The Idea of History (Clarendon Press, Oxford, 1946), especialmente la parte $\mathrm{V}$.

56 M. Oakeshott, Experience and its modes (Cambridge University Press, 1933), pág. 99.

57 Q. Skinner, "Retrospect: Studying rhetoric and conceptual change", en Q. Skinnner, Visions of Politics. 1: Regarding Method (Cambridge University Press, 2002), pág. 177.

58 Craig, n. 13 cit., pág. 42.

59 Ibid. 
rio", continúa Craig, "los pluralistas procedieron entonces a ponerlos a prueba tanto desde un punto de vista descriptivo como prescriptivo. Desde la perspectiva descriptiva, rebatieron la idea de que todo el poder público lo ejercía de hecho el Estado... y, desde la perspectiva prescriptiva, aplaudieron más que condenaron el poder de los grupos sociales". ${ }^{60}$

Esta forma de argumentación, muy típica del análisis de Craig en estas materias, es errónea, tanto si se trata de ciencia, como de historia o teoría política. Su suposición de que existen hechos indiscutibles en este ámbito a los que se puede llegar mediante una investigación empírica objetiva es incorrecta: siempre estamos tratando de ajustar la información a nuestras suposiciones previas, a nuestros pre-juicios, en la materia. Estamos siempre interpretando - exactamente como Craig hace en el pasaje anterior sobre los pluralistas, Dicey y Hobbes-. Y todos los esquemas de interpretación — no sólo los de Craig- son cuestionables. Los razonamientos de Craig están impregnados de una visión bastante "naïf" de la causalidad histórica. ¿Han identificado Craig (o los pluralistas) el origen de la concepción constitucional de Dicey? ¿los planteamientos imaginativos y rigurosos de Hobbes pueden reducirse a una preocupación por la anarquía? ¿dónde está el hecho que evidencie que Dicey (que, por otra parte, no menciona a Hobbes en sus obras The Law of the Constitution y Law and Opinión) estaba influido de manera tan determinante por Hobbes? Del mismo modo que los autores que utilizan un método positivista, Craig está invocando la "teoría" como si fuera un tipo de técnica con la que podamos obtener respuesta a los problemas. En mi opinión, esto es manifiestamente reductor y conduce a soluciones imposibles.

Mientras esta división entre la concepción positivistas y la concepción interpretativista no se supere, no parece que, de momento, podamos hacer mucho por resolver la situación. ${ }^{61}$ Lo más que se puede esperar es que reconozcamos de forma explícita que existe esa división respecto de las cuestiones más básicas relativas a la conceptualización del derecho público y que esa división produce, en muchas ocasiones, errores y malentendidos en la materia. ${ }^{62}$ Desde luego, hay mucho que debatir sobre los métodos de interpretación. El pensamiento liberal normativista, por ejemplo, es claramente interpretativo en su forma de operar y, dado que su influencia se extiende, existen probabilidades de que se pueda desarrollar un debate más auténtico sobre los fundamentos teóricos del derecho público. Pero esta es una forma de pensar que a mi me parece intrínsicamente metafísica y, en la medida en la que apela a la historia,

\section{Ibid}

61 Esta es la diferencia metodológica que, p. ej., reside en el núcleo del actual debate (una ramificación del debate sobre el common law y el ultra vires, igualmente estéril) entre Allan y Craig sobre la lógica de la justificación del control judicial: véase T. R. S. Allan, "Constitutional Dialogue and the Justification of Judicial Review" (2003) 23 O.J.L.S., pág. 563; P. P: Craig, "The Common Law, Shared Power and Judicial Review" (2004) 23 O.J.L.S., pág. 237.

62 Cfr. I. Hacking, The Social Construction of What? (Harvard University Press, Cambridge, Mass., 2000), pág. 31: "Yo no quiero paz entre constructivistas y científicos. Yo quiero comprender mejor sus desacuerdos y por qué, quizás, nunca lleguen a un punto de encuentro". 
como la doctrina histórica de Savigny, lo hace de un modo profundamente antihistórico. ${ }^{63}$ Sin embargo, sólo cuando el contexto se haya librado de residuos del pensamiento positivista seremos probablemente capaces de progresar a través de un debate más constructivo.

\section{CONCLUSIONES}

En esencia, mi opinión es que la propuesta de Cane, de que los ius publicistas debemos centrarnos en los valores más que en la teoría para poder abordar las cuestiones centrales de nuestra disciplina, es incapaz de percibir la complejidad de la materia y de afrontar las dificultades que plantea. Para llegar a esta conclusión, he pretendido mostrar cómo el debate más general (la «guerra académica") se ha desarrollado en unos términos sesgados o asimétricos, y que ha resultado ser una discusión entre seguidores de diferentes tendencias del positivismo sobre cuál es el mejor modo de conceptualizar la relación entre derecho y política. Es muy poco probable que este debate - del que son ejemplo los trabajos de Harlow, Cane y Craig - tenga sentido y resulte interesante para los que mantienen que el derecho es una disciplina interpretativa. La profundidad de la brecha metodológica llega hasta el punto de que aquello que para los autores de una corriente constituye un argumento racional, para los de la otra corriente, sin embargo, no es sino ruido sin sentido.

Por mucho diálogo que se desarrolle entre los positivistas, de la clase que sean, acerca de la importancia de "la teoría" y "los valores" en el derecho público, no parece posible que éste pueda enmascarar su incapacidad para ofrecer una explicación coherente de lo que es el derecho público. Por mi parte, he explicado que entiendo el derecho público como una forma especial del discurso teórico, que define y constituye el ámbito de la política. Se trata de una concepción muy general del derecho público que, indudablemente, presenta también sus propias dificultades metodológicas. Pero al menos permite afrontar de forma coherente y clara la cuestión de la teoría y los valores en el derecho público. De acuerdo con el método interpretativista, la teoría es a los valores lo mismo que la gramática es al vocabulario. El significado de palabras como libertad, democracia y responsabilidad sólo puede determinarse conociendo su gramática, el modo en que se disponen para desplegar efectos en un contexto determinado. Es decir, esos valores abstractos y opinables sólo adquieren un significado más preciso cuando se les sitúa dentro de una construcción teórica concreta. Esas construcciones - practicesson configuraciones de ideas que operan dentro de un contexto histórico y social específico. Las conductas habituales se generalizan a través de dichas construcciones, y a esa reiteración de las conductas, que podemos calificar de

63 Véase E.-W. Böckenförde, "The School of Historical Jurisprudence and the Problem of the Historicity of Law", en E.-W. Böckenförde, State, Society and Liberty: Studies in Political Theory and Constitutional Law (J. A. Underwood traductor, Berg, New York, 1991), cap. 1. 
hábitos de conducta, las he denominado "modelos de pensamiento en derecho público".

Así pues, los modelos de pensamiento en derecho público juegan el papel esencial de actuar como transformadores que convierten los valores abstractos y discutibles en pautas identificables de comportamiento. Estos "modelos" en el derecho público asumen un papel similar al que las "plantillas culturales" (Geertz), ${ }^{64}$ las «formas discursivas" (Foucalt), ${ }^{65}$ los «hábitos" (Bourdieu), ${ }^{66} \mathrm{O}$ las "morfologías ideológicas" (Freeden) ${ }^{67}$ desarrollan en el ámbito social y político en general. El discurso del derecho público puede entenderse como un esfuerzo, mediante el uso del lenguaje, de institucionalizar esos diferentes modelos de pensamiento que compiten entre ellos en las formas de comportamiento de la política.

Cualquier ius publicista con una orientación práctica que haya seguido mi argumentación hasta aquí puede preguntarse con razón: y esto ¿para qué? Si mis reflexiones sobre la teoría y los valores son correctas ¿qué consecuencias derivan de ellas? La respuesta breve es que de la lucha por la libertad y la justicia no deriva nada concreto: con la teoría el mundo sigue siendo precisamente como es. Entonces ¿para qué esta molestia? La mejor respuesta que puedo ofrecer exige realizar una distinción entre dos tipos de papeles: el de actor y el de académico. Mientras los actores en el ámbito del derecho público están motivados por el deseo de promover sus propios objetivos ideológicos, los académicos desempeñan un papel más comedido. Los académicos tratan de identificar «los modelos, los esquemas de pensamiento en el derecho público, y el modo en que éstos dan forma a lo políticamente posible, ${ }^{68}$ mientras que los actores buscan introducir cambios en los consensos básicos. Con todo, no hay que exagerar estas diferencias. Con frecuencia, los actores consideran que sólo son capaces de actuar de forma efectiva en el ámbito del derecho si han internalizado previamente las pautas de las conductas imperantes y han adquirido un conocimiento reflexivo suficiente del discurso teórico en la materia, que les permita moldear el derecho público de acuerdo con sus propios valores y su propio modelo de pensamiento sobre el derecho público. Y, a pesar de que el trabajo académico es más limitado, sigue siendo un esfuerzo imaginativo y constructivo. Lo que hay que subrayar, sin embargo, es que, de forma ca-

64 C. Geertz, "Ideology as a Cultural System", en D. E. Apter, ed., Ideology and Discontent (Free Press, New York, 1964), pág. 63.

65 M. Foucalt, The Archaeology of Knowledge (A. M. Sheridan Smith, traductor, Routledge, London, 1989), cap. 2.

66 P. Bourdieu, The Logic of Practice (Richard Nice, traductor, Stanford University Press, Standford, California, 1990), pág. 59.

67 M. Freeden, Ideologies and Political Theory (Clarendon Press, Oxford, 1996).

68 Freeden, ibid., pág. 39. Véase también M. Freeden, "Practising Ideology and Ideological Practices" (2000) 48, Political Studies, pág. 302 a 304: "estudiar una ideología es caracterizar, aclarar y descodificar las formas a través de las cuales los colectivos de hecho piensan en términos políticos, los modos mediante los cuales intencionadamente practican el arte del pensamiento político y de forma no intencionada expresan los elementos sociales a partir de los cuales se ha desarrollado ese pensamiento". 
tegórica, el rol académico no está interesado en «la sustitución crítica (del marco existente) con estructuras más coherentes o con posiciones preferibles normativamente... sin relación con los contextos en los que se produce el pensamiento políticon. ${ }^{69}$ En la medida en que el académico pretende hacer eso, ya sea abogando explícitamente por una teoría normativa del derecho público o exigiendo una reforma del sistema recurriendo a su propia experiencia, entonces, está asumiendo el papel que le corresponde desempeñar al actor.

Desde luego, no hay razón por la que cualquiera que trabaja en este ámbito - ya sea académico o actor- no pueda cambiar de rol, especialmente en un campo de la importancia social y la complejidad del derecho público. Pero existe una razón específica por la que estos roles no deben confundirse, y es la de que estos discursos, en competencia entre ellos, es todo lo que tiene el derecho público. No hay una verdad metafísica, no hay pautas trascendentes de corrección que provengan de otro tipo de sujetos, y hay muy poco que, por la vía del conocimiento técnico especializado, permita a los "expertos" ofrecer soluciones científicas a los problemas del derecho público. El derecho público comprende un conjunto de actuaciones cambiantes relativas a la actividad política y de diversos, aunque similares, modelos de argumentación también cambiantes. La contribución de los académicos consiste pura y simplemente en la teoría, en el sentido de ofrecer una explicación del derecho público tal y como se practica, y de un valor explicativo tal que resulte convincente. ${ }^{70}$ Pero esta posición académica es, en el mejor de los casos, sólo el punto de partida para los actores. Ellos operan principalmente en el plano de los valores, y les corresponde construir el derecho público de acuerdo con los resultados valorativos deseados. Y desde esta perspectiva interpretativa, la relación entre teoría y valores en el derecho público es precisamente la contraria de la que propone Cane.

ABSTRACT. This paper analyses the recent debate on English public law scholarship about the theory and values in public law. Therefore, it reviews the main elements of that debate, offers an analysis of the issues at stake and provides an explanation of the significance of the various positions taken on these questions. The analysis focuses on the contributions of some relevant authors, Peter Cane, Paul Craig and Carol Harlow, and it is structured on three basic questions: What is public law? How can values contribute to understand public law? And what is the place and task of theory in public law?

69 Freeden, ibid.

70 Puesto que mi objetivo en los dos trabajos Public Law and Political Theory, n. 4 cit., y The Idea of Public Law, n. 35 cit., era académico en este sentido, la crítica de Dyzenhaus de que mi trabajo era de algún modo representativo de "la izquierda" (sea lo que fuere lo que esto significa) resulta así fuera de lugar: D. Dyzenhaus, "The Left and the Question of Law" (2004), 17 Canadian Journal of Law and Jurisprudence, pág. 7. 